\title{
Yielding in soft clay at Bäckebol, Sweden
}

\author{
D. M. WOOD (1980). Géotechnique 30, No. 1, 49-65
}

\author{
Professor F. Tavenas and S. Leroueil, Laval \\ University, Quebec
}

The limit state concept, developed to provide a logical framework for the analysis of clay behaviour, is increasingly used in interpreting field observations. The Author presents an interesting application of this concept to the analysis of the well-documented Bäckebol field tests (Sällfors, 1975). The Paper obtains 'clues to shape of yield surface' in situ and discusses the generation of pore pressures in a soft clay foundation, based on a simplified theoretical limit state model.

We have accumulated a large number of experimental data on yield surfaces in intact natural clays as well as on pore pressure behaviour in clay foundations. The data are at variance with some of the Author's assumptions, statements and conclusions.

\section{SHAPE OF YIELD SURFACE IN NATURAL CLAYS}

The original and modified Cam clay models (Roscoe \& Burland, 1968), as well as the simplified form considered by the Author, have been developed for and apply strictly to isotropic remoulded clays. The circular yield surface (Fig. 1(a)) characterizes the behaviour of such an artificial material. In artificial, anisotropically consolidated clays, the shape of the yield surface reflects the anisotropic stress history and it is different from that shown in Fig. 1(a) (Lewin, 1973; Parry \& Nadarajah, 1973).

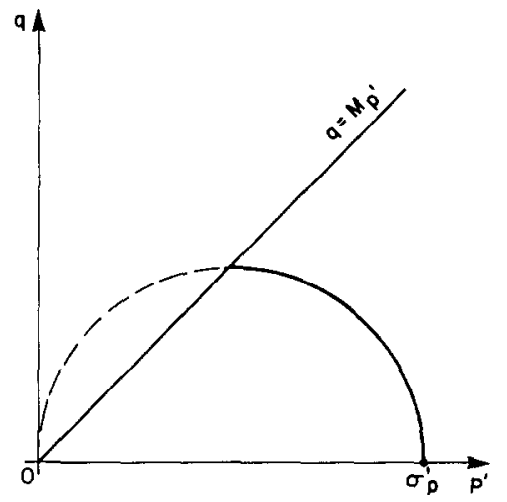

(o)
Natural clays have been consolidated under $K_{0}$ stress conditions and subsequently submitted to a variety of geological processes such as erosion, ageing, thixotropic hardening, cementation and leaching. The present shape of the yield surface in natural materials reflects the characteristics of the clay structure resulting from these processes. Compiling data on a variety of natural clays, Leroueil \& Tavenas (1977) have shown that the shape of their yield surface is typically as shown in Fig. 1(b). The effect of anisotropy is evident, the yield surface being more or less centred on the $K_{0}$ line. This effect can best be described by the ratio of the preconsolidation pressure $\sigma_{\mathrm{p}}$ ' to the isotropic yield condition $\sigma_{\text {piso }}{ }^{\prime}$. This ratio has been determined for 23 natural clays from various locations in the world; on average it is of the order of 1.6 with minimum and maximum values of 1.2 and $2 \cdot 1$ respectively. In all cases this ratio is different from that implied in the Author's model. We suggest that the shape of the yield surface in natural clays is now fairly well established qualitatively, as shown in Fig. 1(b). Consequently, the application of isotropic yield surfaces, such as that in Fig. 1(a), to the analysis of natural clay behaviour is not justified.

\section{PORE PRESSURE GENERATION DURING CONSTRUCTION}

As noted in the Paper, the Bäckebol test data clearly evidence the rapid development of a significant pore pressure dissipation in the early

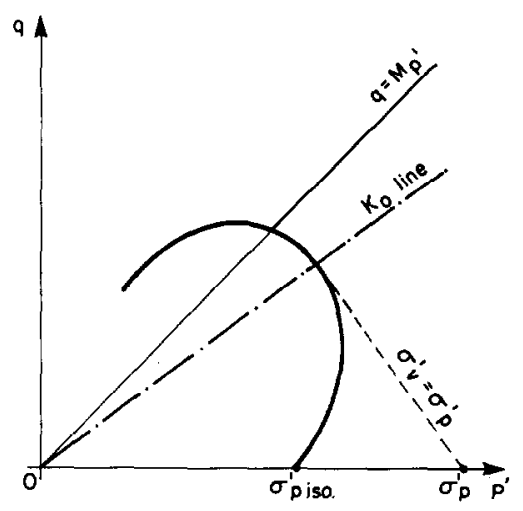

(b)

Fig. 1. Shapes of yield curves: (a) for remoulded isotropically consolidated clays: (b) for natural undisturbed clays 


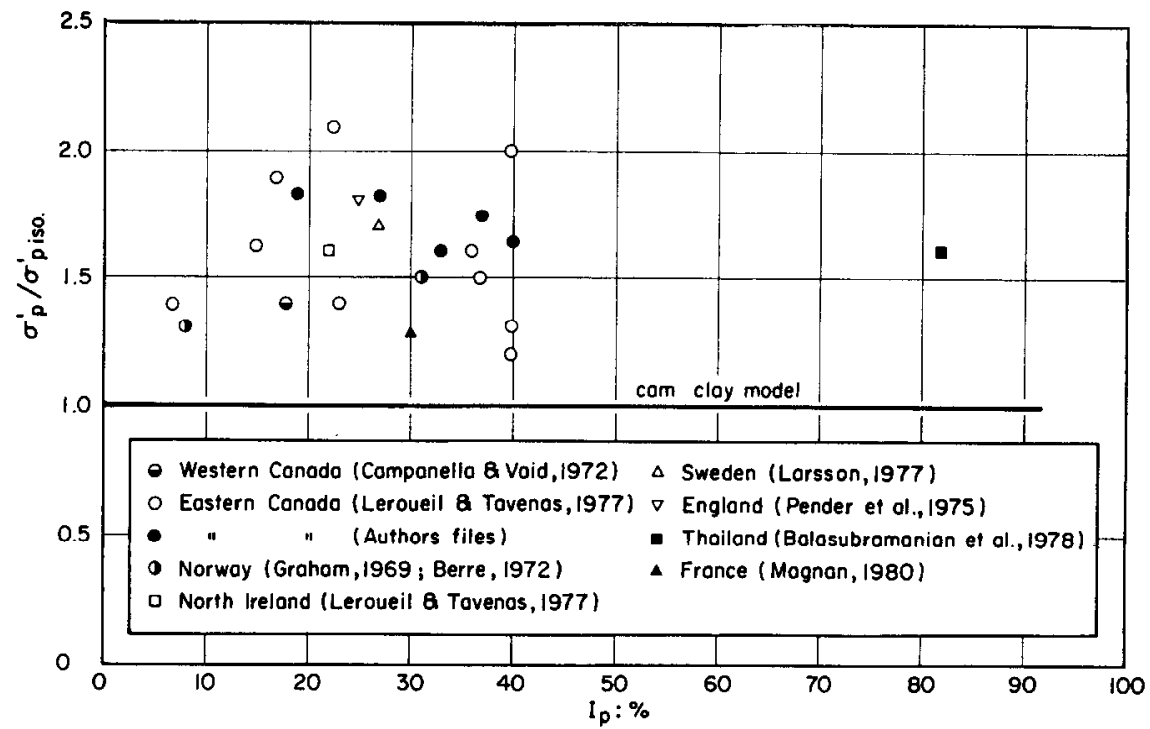

Fig. 2. Typical shape parameters of yield curves of natural undisturbed clays

stages of load application, particularly in the upper $4 \mathrm{~m}$ of the clay foundation. The Bäckebol I data lead to the same conclusion, in spite of the faster rate of load application of $1-3 \mathrm{kPa}$ per day rather than $0.8 \mathrm{kPa}$ per day for Bäckebol II. The observed pore pressure increments for the two tests during the early stages of construction are shown in Fig. 3; at depths less than $5 \mathrm{~m}$, the observed $\delta u / \delta \sigma$ are significantly less than the theoretical value of $\delta u=\delta p$. For Bäckebol II, $\delta u / \delta \sigma$ is apparently equal to zero, possibly as a result of the combined effects of water table variations and consolidation. For Bäckebol I, $\delta u / \delta \sigma$ is higher, but the $\delta u / \delta \sigma=\mathrm{f}(z)$ curve has the typical shape of a consolidation isochrone. This observation is in agreement with an earlier study by Leroueil et al. (1978) who indicated that a rapid initial consolidation is a phenomenon of general occurrence, having been observed in more than 30 case histories involving all sorts of natural clays.

The effect of this important initial consolidation is to produce a rapid increase in the effective stresses up to the point where they reach the yield surface of the clay, which then becomes normally consolidated. The Author has carried out a stress analysis to evaluate the $p^{\prime}, q$ yield stress conditions for the Bäckebol II test. The results of this analysis, presented in Fig. 8 of the Paper, may be dependent to a large degree on the assumptions made in the stress analysis. The technique described by the Author for obtaining $K_{0} \simeq 0.76$ appears

Fig. 4. Comparison between threshold vertical stress deduced from pore pressure observations and preconsolidation pressure in clay foundation

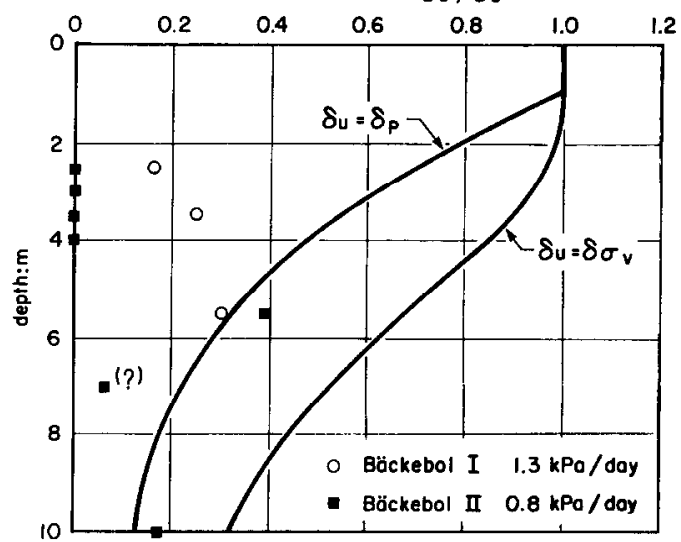

Fig. 3. Pore pressures under Bäckebol embankments during early loading

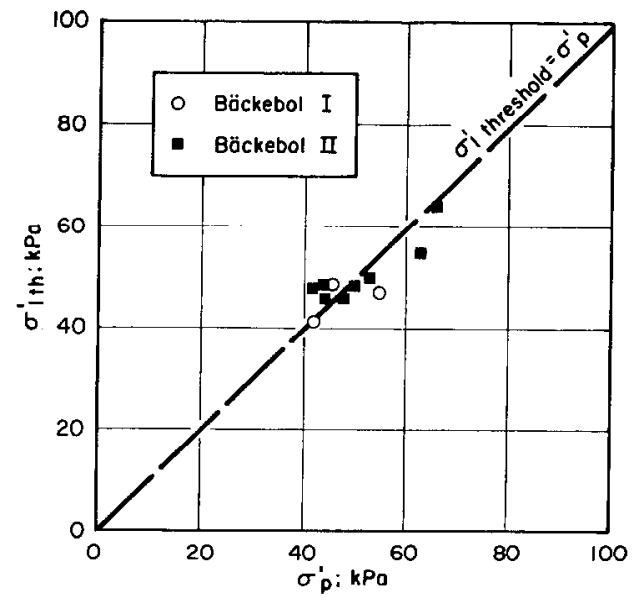




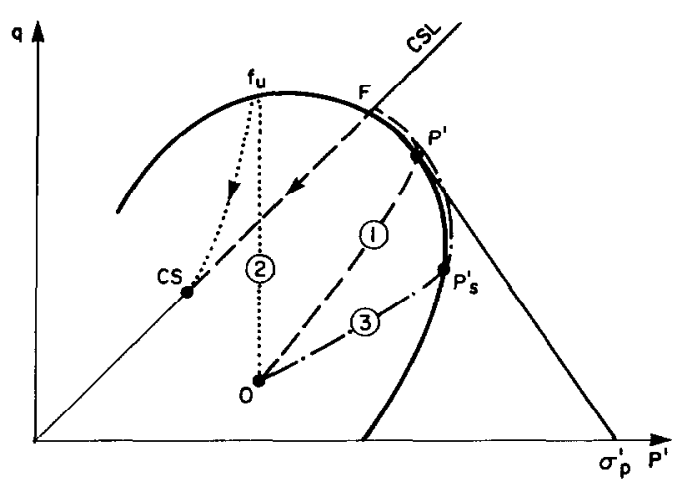

Fig. 5. Possible effective stress paths in clay foundation

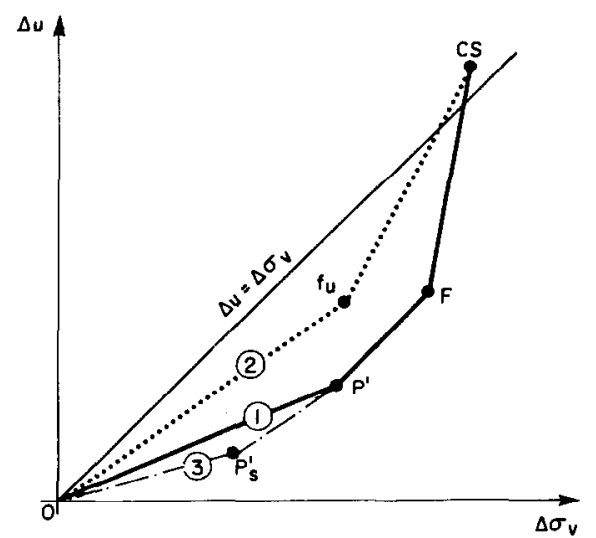

Fig. 6. Possible pore pressure responses in clay foundation

questionable. Sällfors (1975) has shown that the stress state in the oedometer may be different from a $K_{0}$ condition in an overconsolidated clay; Tavenas et al. (1975) have pointed out the near impossibility of determining $K_{0}$ accurately in situ. The total horizontal stresses are strongly dependent on the assumption on the stress-strain behaviour of the foundation, in particular on the values of Poisson's ratio v. The Author has assumed an isotropic, perfectly elastic behaviour; this is a common, but disputable, approach in view of the anistropy of natural clays. The selection of the proper Poisson's ratio for a total stress analysis should be a major problem in the case of a partially drained response such as that of the Bäckebol foundation. It is not clear from the Paper whether the Author has used a $v$ value corresponding to a perfectly undrained or a fully drained condition. It is likely that the relevant values of Poisson's ratio were different from any of these assumptions, so that the actual total horizontal stresses must have differed from those used to obtain Fig. 8 in the Paper. We thus question the conclusion on the

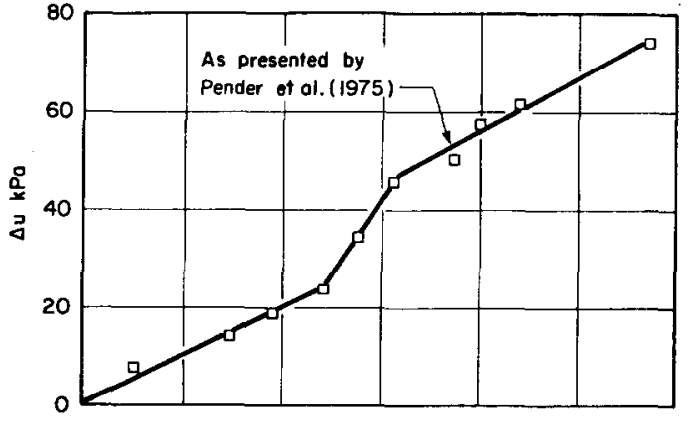

(0)

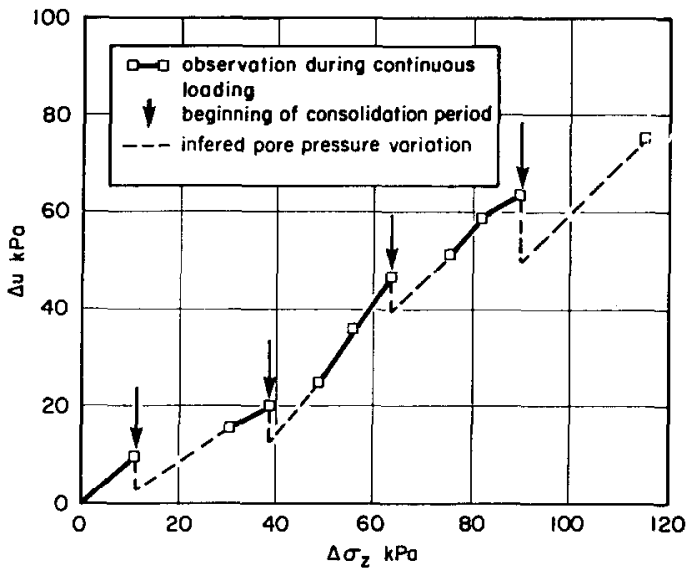

(b)

Fig. 7. Pore pressure response under the Canvey Island embankment: (a) as interpreted by Pender et al. (1975); (b) considering actual construction schedule

shape of the yield surface drawn by the Author in Fig. 8(b).

In their analysis of 30 case histories, Leroueil et al. (1978) noted that only the total vertical stress under the centre of the loaded area could be computed with sufficient accuracy. Analysing the development of the vertical effective stresses during construction, with due consideration to the actual shape of the yield surface in natural clays (Fig. 1(b)), they concluded that yielding generally occurs in situ when the vertical effective stress becomes equal to the preconsolidation pressure $\sigma_{\mathrm{p}}{ }^{\prime}$. The Bäckebol test results are no exception. The vertical effective stresses at yielding $\sigma_{1 \mathrm{th}}$ ' for Bäckebol I and II are compared with the preconsolidation pressures $\sigma_{\mathrm{p}}{ }^{\prime}$ at the corresponding depths in Fig. 4. The agreement is within $\pm 15 \%$ of a perfect correlation, i.e. excellent in view of the unavoidable inaccuracies in the determination of $\sigma_{\mathrm{p}}{ }^{\prime}, \sigma_{\mathrm{v}}$ and $u$. We suggest that the section of the yield surface which is of interest at yielding in a clay foundation corresponds to a $\sigma_{\mathrm{v}}{ }^{\prime} \simeq \sigma_{\mathrm{p}}{ }^{\prime}$ line shown in Fig. 1(b).

The assumptions made by the Author in 
analysing the post-yield pore pressures are subject to question. The basis of the Author's analysis is presented in Figs 3 and 4 of the Paper. Between B and $C$ the effective stresses in the yielded clay move along the current yield surface; between $C$ and $D$ failure is assumed to occur in a perfectly plastic manner, which implies that $\Delta u=\Delta \sigma_{\mathrm{v}}$. This type of behaviour may be representative of remoulded clays but it is questionable for natural clays. Tavenas \& Leroueil (1977) noted that natural clays are characterized by a relatively high stiffness in the overconsolidated state and by a critical state condition located not on the yield surface but within it. As a consequence the apparent displacement of the current yield surface between $B^{\prime}$ and $C^{\prime}$ should be negligible for all practical purposes and failure at $C^{\prime}$ should be followed by a significant strain softening down to the critical state. Leroueil et al. (1978) considered the various effective stress paths possible in a clay foundation during load application.

The most common case, encountered in clays with OCR less than 2.5 at all locations where the consolidation is significant, is that represented by the stress path 1 in Fig. 5. After an initial, partially drained response, yielding occurs at $\mathrm{P}^{\prime}$. At this point the compressibility of the clay is considerably increased, its coefficient of consolidation is decreased accordingly, and further construction is associated with an essentially undrained response. The effective stress path then follows the current yield surface, which corresponds to a stress path with $\sigma_{\mathrm{v}}{ }^{\prime}=\sigma_{\mathrm{p}}{ }^{\prime}=C^{\text {ste }}$ the $\bar{B}$ coefficients computed by Leroueil et al. (1978) from 70 field observations are equal to $1 \cdot 04 \pm 0 \cdot 16$. When local failure develops at $F$ strain softening is initiated towards the critical state CS; the strain softening in situ must be associated with an increase in the total horizontal stresses and with a significant generation of excess pore pressures $\left(\Delta u \gg \Delta \sigma_{\mathrm{v}}\right)$.

The complete pore pressure response is shown by curve 1 in Fig. 6; it has been observed in a variety of case histories. At locations in soft clay foundations where the initial pore pressure dissipation may be negligible, an undrained stress path such as curve 2 in Fig. 5 would be followed. Failure would start to develop at $f_{\mathrm{u}}$ with strain softening down to the critical state CS; again large pore pressure increments would develop near failure. The corresponding pore pressure response is shown by curve 2 in Fig. 6. In clays with an OCR in excess of 2.5 or in the case of a very slow load application the initial pore pressure dissipation would be more important, leading to an effective stress path (curve 3 ) and to yielding at $P_{\mathrm{s}}^{\prime}$. The pore pressure response just after yielding would correspond to $\Delta u<\Delta \sigma_{v}$ (curve 3 in Fig. 6).
The different pore pressure responses shown in Fig. 6 have been observed in the case histories considered by Leroueil et al. (1978), the response curve 1 being applicable to more than $90 \%$ of all field observations. The type of response indicated in Fig. 4 of the Paper (in particular the final response $C D$ ) has not been observed. The Author notes that Pender, Parry \& George (1975) reported a pore pressure response such as that shown in his Fig. 4. The construction pore pressures at Canvey Island are presented by Pender et al. (1975) in Fig. 7 (a). However, detailed analysis of the field data indicates that the construction of the Canvey Island fill was not continuous, but that four periods of consolidation were allowed at different stages, which resulted in significant porc pressure dissipations. Accounting for this, the pore pressure response might be interpreted as in Fig. 7(b) which is consistent with curve 1 in Fig. 6. Yielding would have occurred during the second consolidation period with post-yield pore pressure coefficients $\bar{B}$ of $1 \cdot 0-1 \cdot 3$. The Åsrum test data (Hoeg, Andersland \& Rolfsen, 1969) also support the conclusions of Leroueil et al. (1978) rather than the Author's model as yielding occurred during a long consolidation period between two stages of construction.

We would also question the validity of Fig. 11 of the Paper. In computing the pore pressures, the Author assumes that the coefficient of consolidation of the clay is not changed at yielding. This is contrary to all available laboratory and field observations. Indeed $C_{\mathrm{v}}$ is a function of the constrained modulus $M=\Delta \sigma / \Delta \varepsilon$ of the clay. This modulus can be reduced by a factor of no less than 3 in destructured clays and as much as 100 in naturally structured clays. Tests by Sällfors (1975) indicate a reduction by a factor of 15-20 of the constrained modulus of the Bäckebol clay at yielding. As a result $C_{\mathrm{v}}$ is reduced by more than one order of magnitude and the rate of the pore pressure dissipation is changed accordingly. Neglecting this fact must result in an erroneous estimation of the construction pore pressures presented in Fig. 11 of the Paper.

The analysis of case histories by Leroueil et al. (1978) has led to a rather simple empirical method of predicting the end of construction pore pressure under the centre line of a stable embankment (FS $>1 \cdot 3$ ). According to this method, which corresponds to the response curve 1 in Fig. 6

$$
\Delta u=\Delta \sigma_{\mathrm{v}}-\left(\sigma_{\mathrm{p}}{ }^{\prime}-\sigma_{\mathrm{vo}}{ }^{\prime}\right)
$$

The validity of this equation has subsequently been checked on a variety of projects.

\section{REFERENCES}

Balasubramanian, A. S., Hwang, Zue-Ming, Waheed, U., Chaudry, A. R. \& Li, Y. G. (1978). Critical stat? 
parameters and peak stress envelopes for Bangkok clays. Q. Ji Engng Geol. 11, No. 3, 219-232.

Berre, T. (1972). Sammenheng mellom tid, deformasjoner og spenninger for normal-konsoliderte marine leirer. Proceedings of Nordic conference on soil mechanics, Trondheim.

Campanella, R. G. \& Vaid, Y.(1972). A simple $K_{0}$ triaxial cell. Can. Geotech. J. 9, No. 3, 249-260.

Graham, J. (1969). Laboratory results from Mastemyr quick clay after reconsolidation to the in situ stresses. Internal report F-372-5. NGI.

Hoeg, K., Andersland, O. B. \& Rolfsen, E. N. (1969). Undrained behaviour of quick clay under load tests at Åsrum. Géotechnique 19, No. 1, 101-115.

Larsson, R. (1977). Basic behaviour of Scandinavian soft clays. Report 4. Swedish Geotechnical Institute.

Leroueil, S. \& Tavenas, F. (1977). Discussion on Geotechnical properties of the Belfast estuarine deposits, by Crooks and Graham. Géotechnique 27, No. 3, 441447.

Leroueil, S., Tavenas, F., Mieussens, C., \& Peignaud, M. (1978). Construction pore pressures in clay foundations under embankments-Part II: generalized behaviour. Can. Geotech. J. 15, No. 1, 66-82.

Lewin, P. I. (1973). The influence of stress history on the plastic potential. Proceedings of symposium on role of plasticity in soil mechanics, Cambridge, 96-105.

Magnan, J. P. (1980). Personal communication.

Parry, R. M. G. \& Nadarajah, V. (1973). A volumetric yield locus for lightly overconsolidated clay. Géotechnique 23, No. 3, 450-453.

Pender, M. J., Parry, R. H. G. \& George, P. J. (1975). The response of a soft clay layer to embankment loading. Proc. 2nd Aust. Conf. Geomech., Brisbane 2, 169-173.

Roscoe, K. M.\& Burland, J. B. (1968). On the generalised stress-strain behaviour of 'wet' clay. Enyineering plasticity (Heyman, J. and Leckie, F. A., Eds), 535-609. Cambridge University Press.

Sällfors, G. (1975). Preconsolidation pressure of soft, highplastic clays. PhD thesis, Chälmers Tekniska Högskola, Göteborg.

Tavenas, F., Blanchet, G., Leroueil, S., Roy, M. \& La Rochelle, $P$. (1975). Difficulties in the in situ determination of $K_{0}$ in soft sensitive clays. In situ measurement of soil properties 1, 450-476. New York: American Society of Civil Engineers.

Tavenas, F. \& Leroueil, S. (1977). Effect of stresses and time on yielding of clays. Proc. 9th Int. Conf. Soil Mech., Tokyo 1, 319-326.

\section{Author's reply}

By 'the limit state concept' I assume Professor Tavenas and Mr Leroueil mean ideas of plasticity and yielding. It is not clear that it is appropriate to assume that limit state and yield are identical. The terminology of limit states is helpful to the engineer designing a prototype structure who may want to distinguish a serviceability limit state, at which deformations become excessive, from an ultimate limit state, at which the structure fails. It is not helpful to talk about a limit state being reached when a sample yields in a single element test in the laboratory: the dispassionate laboratory observer is interested to find out as much as he can about the behaviour of the sample and will not be alarmed as soon as he detects yield. Similarly, the occurrence of local yielding of certain elements beneath a structure on soft clay need not necessarily cause disquiet to the designer of the structure. The onset of yield at one section of a steel portal frame is unlikely to put the frame in a limit state: formation of a plastic hinge at one section may be more critical. Local yielding of soil elements does not imply that a limit state for the soil structure has been attained.

The Writers are confused and contradictory in their criticism of the shape of yield surface deduced from the Bäckebol test. Certainly the modified Cam clay model of Roscoe \& Burland (1968) assumes a semi-elliptical yield curve and, as mentioned in the Paper, this is unlikely to provide a satisfactory complete yield curve for in situ anisotropically consolidated clays. However, there seems little point in introducing unnecessary complexities into a model. Cam clay models have proved reasonably successful for predicting performance of loads on soft clay (e.g. Wroth, 1977) precisely because the soil elements which are actually deforming under the load are being subjected to effective stress paths which intersect the top part of the yield curve, so that locally the shape of the semi-elliptical yield curve may be adequately accurate. That is why the yield curves in Figs 1, 3 and 9 of the Paper were shown dashed except in the region of interest. The Writers suggest that $\sigma_{\mathrm{v}}{ }^{\prime}=\sigma_{\mathrm{vc}}{ }^{\prime}$ provides a good fit to the field observations, but they cannot really be proposing that this line any more than the semiellipse provides an adequate estimate of the shape of the yield curve for the anisotropic clay at lower stress ratios $q / p^{\prime}$. This point was discussed in the Paper (p. 57). A comparison of different proposals is shown in Fig. 1.

The Writers have criticized the Author's use of a simple elastic analysis to calculate stresses in the soil but do not state what analysis they have used. Obviously it is not being suggested that the soil throughout the foundation under the tank is behaving isotropically and elastically, but again there seems little point in postulating a more elaborate model for making rather simple deductions about the yielding of the clay.

The Writers' statements about pore pressure generation are directed at the simple model described by Parry \& Wroth (1977) which was introduced in the Paper largely to show that changes in the rate of pore pressure generation with applied surface load will occur when the effective stress path at a given element reaches the yield curve relevant to that element. (Once it reaches the yield curve hardening of the soil occurs 


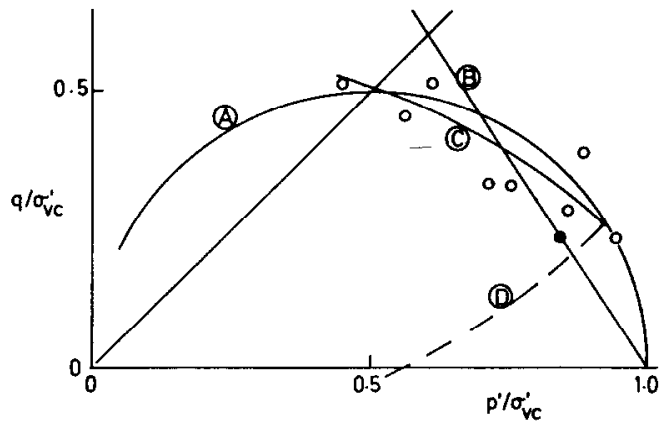

A. Semi-ellipse proposed by Roscoe \& Burland (1968)

B. Yield condition proposed by the Writers, $\sigma_{v}^{\prime}=\sigma_{v c}^{\prime}$

C. Yield curve proposed for Bäckebol results by the Author

D. Expected form of yield curve at low values of $q / p^{\prime}$

Fig. 1. Comparison of proposed yield curves

and the undrained condition is maintained by a balance between elastic expansion and plastic compression, so it is not strictly correct to say that the effective stress state moves along the current yield curve.) It is not clear that the Writers' interpretation of the results of the Canvey Island loading test is more plausible than that of Pender, Parry \& George (1975).

The coefficient of consolidation $c_{v}$ is uscful in the elementary Terzaghi analysis of one-dimensional consolidation and is a ratio of a rate of pore pressure dissipation parameter (the permeability $k$ ) to a rate of pore pressure generation parameter (the coefficient of volume compressibility $m_{v}$, which is a rather special constrained compliance). In general field situations (and Bäckebol is no exception) loading and consolidation will not be one-dimensional-the ground around the loading cannot provide complete lateral restraint. In any analysis of the general situation, therefore, it is necessary to have a more general model for the rate of pore pressurc gencration-and in this case, modified Cam clay might well prove adequatewhile the rate of pore pressure dissipation will still be governed by the (possibly anisotropic) permeability $k$. The permeability will change as the void ratio of the soil changes, and might also be affected by major structural rearrangements of the soil particles. The mere fact that the effective stress path reaches the yield curve will lead to an increase in the rate of pore pressure generation-the model is now indicating generation of pore pressures to resist plastic volumetric collapse-but will not produce any change in the rate of pore pressure dissipation until a major change of particle arrangement has occurred. The coefficient $c_{\mathrm{v}}$ drops after yield in an oedometer because $m_{\mathrm{v}}$ increases, not because $k$ decreases.
Before yield, elastic generation of pore pressures is expected. If the rate of increase of surface load is $\delta \sigma / \delta t$ then the expected rate of pore pressure generation is

$$
\frac{\delta u}{\delta t}=\frac{1}{3}\left(\alpha_{v}+2 \alpha_{h}\right) \frac{\delta \sigma}{\delta t}
$$

In fact the observed pore pressures at Bäckebol seem on the whole to stay constant, with no buildup of pore pressure occurring. Consequently the permeability of the clay must be such that the pore pressure gradients that arise are sufficient to ensure pore pressure dissipation.

When a particular soil element yields, the pore pressure at that element is expected to start increasing at a faster rate. The rate of increase of surface load $\delta \sigma / \delta t$ is constant, but plastic compression at yield leads to the generation of extra pore pressures. However, until major changes of soil structure have occurred, the permeability will not drop and it might be expected that if conditions before yield were such that pore pressures

$$
\frac{\delta u}{\delta t}=\frac{1}{3}\left(\alpha_{\mathrm{v}}+2 \alpha_{\mathrm{h}}\right) \frac{\delta \sigma}{\delta t}
$$

failed to build up, then whereas the total pore pressure generation expected is

$$
\frac{\delta u}{\delta t}=\frac{1}{3}\left(\alpha_{\mathrm{v}}+2 \alpha_{\mathrm{h}}\right) \frac{\delta \sigma}{\delta t}+\frac{1}{m}\left(\alpha_{\mathrm{v}}-\alpha_{\mathrm{h}}\right) \frac{\delta \sigma}{\delta t}
$$

one will only actually see the second part of this

$$
\frac{\delta u}{\delta t}=\frac{1}{m}\left(\alpha_{\mathrm{v}}-\alpha_{\mathrm{h}}\right) \frac{\delta \sigma}{\delta t}
$$

because the permeability is sufficient for the other part to continue to dissipate. In fact, the rate of pore pressure dissipation might well increase if the occurrence of yield were to permit higher pore pressure gradients to arise.

\section{REFERENCES}

Parry, R. H. G. \& Wroth, C. P. (1977). Shear properties of soft clays. Report presented at International Symposium on soft clay, Bangkok.

Pender, M. J., Parry, R. H. G. \& George, P. J. (1975). The response of a soft clay layer to embankment loading. Proc. 2nd Aust.-N.Z. Conf. Geomechanics, Brisbane 2, $169-173$

Roscoe, K. H. \& Burland, J. B. (1968). On the generalised stress-strain behaviour of 'wet' clay. Engineering plasticity, (Heyman, J. and Leckie, F. A., Eds), 535609. Cambridge University Press.

Wroth, C. P. (1977). The predicted performance of a soft clay under a trial embankment loading based on the Cam-clay model. Finite elements in geomechanics (Gudehus, G., Ed.), 191-208. New York: Wiley. 